\title{
Manejos para redução de perdas em pré-colheita de canola sob elevada pluviosidade
}

\author{
Management to reduce losses in canola pre-harvest under high rainfall \\ Carlos Augusto Pizolotto ${ }^{\star}$, Walter Boller ${ }^{1}$, Nadia Canali Lângaro \& Gilberto Omar Tomm² \\ ${ }^{1}$ Universidade de Passo Fundo, Passo Fundo, RS, Brasil. *Autor para correspondência: carlos47@ksu.edu. \\ ${ }^{2}$ Empresa Brasileira de Pesquisa Agropecuária, Passo Fundo, RS, Brasil.
}

Submissão: 08/07/2016 / Aceite: 09/05/2018

\begin{abstract}
RESUMO
A canola destaca-se como importante alternativa econômica, pois constitui matéria prima na produção de óleo para o consumo humano, como para produção de biodiesel. No entanto a operação de colheita é um entrave à ampliação do cultivo desta brassicácea que necessita ser solucionado. O objetivo do trabalho foi avaliar cinco sistemas de manejo de colheita mecanizada de canola, com ou sem a aplicação de um adesionante, em relação às perdas de pré-colheita e colheita, rendimento de grãos e teor de água nos grãos colhidos. O híbrido de canola utilizado foi o Hyola 61, sendo semeado com espaçamento entrelinhas de $0,45 \mathrm{~m}$, e com densidade de 40 sementes viáveis $\mathrm{m}^{-2}$. Os tratamentos resultaram das combinações entre diferentes manejos da colheita e uso de um adesionante. Os manejos adotados foram: M1 - colheita com corte direto no ponto de maturação natural (testemunha); M2 - dessecação química prévia com diquat; M3 - dessecação química prévia com glufosinato de amônio; M4 - corte-enleiramento, e M5 - aplicação de etefom. Os manejos da colheita com corte-enleiramento, dessecação química prévia, e aplicação de etefom, isoladamente ou combinados ao adesionante, reduzem as perdas na colheita e permitem obter maiores rendimentos de grãos de canola, além de reduzirem o teor de água nos grãos colhidos, sob condições de pluviosidade excessiva.
\end{abstract}

PALAVRAS-CHAVE: Brassica napus L. var. oleifera, Hyola 61, rendimento de grãos.

\begin{abstract}
Canola stands out as an important economic alternative as it is a source for the production of oil for human consumption, and in its use for the production of biodiesel. However mechanized harvesting is an obstacle to the expansion of the cultivation of this brassicaceae that need to be solved. The objective of this work was to evaluate five canola mechanized harvesting management systems, with or without the application of a sealant, compared to losses of preharvest and harvest, grain yield and water content in the grains. The canola hybrid Hyola 61 was used, being seeded with row spacing of 0.45 meters, and density of 40 viable seeds $\mathrm{m}^{-2}$. The treatments resulted from the combination of different management processes combined with a sealant. The adopted managements were: M1 - harvesting with cut straight to the natural maturation point (untreated); M2 - previous chemical desiccation with diquat; M3 - previous chemical desiccation with ammonium glufosinate; M4 - cut-windrowing, and M5 - ethefom application. The harvest managements with cut-windrowing, previous chemical desiccation, and applying etefom, singly or in combination to sealant, reduced the grain losses in the harvest allowing higher yields to be obtained, and also reducing the water content in the grains, under conditions of excessive rainfall.
\end{abstract}

KEYWORDS: Brassica napus L. var. oleifera, Hyola 61, grain yield.

\section{INTRODUÇÃO}

A busca por espécies que possam ser utilizadas em esquemas de rotação de culturas tem sido grande nos últimos anos, principalmente no inverno, nos estados do Sul do Brasil (KRÜGER et al. 2011). O país importou em 2012 aproximadamente 42.500 toneladas de canola e derivados, compreendendo sementes, grãos, óleo bruto e refinado, tendo produzido em uma área de 48.704 hectares aproximadamente 60.000 toneladas nesse mesmo ano (CONAB 2013, DE MORI et al. 2014).

A canola pode ser considerada uma boa opção para fazer parte de um esquema de rotação de culturas. Neste sentido, estudos relacionados ao melhoramento genético e ao rendimento de grãos de 
canola têm sido conduzidos em diferentes centros de pesquisa, tendo como prioridade a seleção de genótipos mais produtivos em um maior número de ambientes (GARRAFA 2005).

Em relação aos híbridos cultivados no Brasil, principalmente, no Sul do país, a colheita é a etapa mais crítica, pois a maturação desses híbridos ocorre de baixo para cima na haste principal e nos ramos secundários (acrópeta) e de maneira desuniforme. Após o amadurecimento ocorre a abertura das síliquas, pois são frutos que apresentam deiscência natural, com perdas pela queda de grãos no solo (CONTERJNIC et al. 1991).

Atualmente, são três os manejos de colheita adotados pelos produtores: colheita com corte direto na maturação natural, dessecação química prévia e posterior colheita com corte direto, e colheita por meio de corte-enleiramento (TOMM et al. 2009).

O corte-enleiramento reduz as perdas de pré-colheita e colheita, o teor de água nos grãos colhidos e as perdas por degrane que ocorrem a partir da maturidade fisiológica das plantas, quando há ocorrência de temporais de vento, chuvas torrenciais e granizo as vésperas da colheita (TOMM 2005). No entanto, um importante fator deve ser levado em consideração para se determinar o período ideal do corte-enleiramento, sendo esse, a verificação da cor dos grãos dentro das síliquas localizadas na parte superior do caule das plantas (CANOLA 2012). Quando 60\% dos grãos mudaram da cor verde para marrom, é um indicativo de que as plantas atingiram a maturidade fisiológica, sendo que neste ponto o teor de água nos grãos está em torno de 35\%; então imediatamente deve-se iniciar o processo de corte-enleiramento das plantas (CANOLA 2014).

Quando se opta pelo uso de herbicidas dessecantes em pré-colheita, o melhor momento para a aplicação é quando $60-75 \%$ dos grãos mudarem de cor (da cor verde para a cor marrom) e o intervalo entre a pulverização e a colheita deve ser no mínimo de sete dias (BOLLER et al. 2012).

Os herbicidas dessecantes promovem a maturação mais uniforme da cultura, controlam plantas daninhas que poderiam de alguma forma dificultar o processo de colheita, além de facilitar o processo de colher e semear no limpo. Os herbicidas utilizados nesse trabalho têm modo de ação por contato. O diquat é um inibidor do fotossistema I, e atua reduzindo drasticamente o teor de água da biomassa verde, ocasionando rápida secagem das plantas (LACERDA et al. 2003). Já o glufosinato de amônio promove o acúmulo de amônia nas plantas tratadas, apresentando menor velocidade na redução do teor de água das plantas tratadas, reduzindo as perdas por degrana (WENDLER et al. 1992).

A aplicação de desfolhantes, como o etefom, surge como um método alternativo para a redução das perdas de grãos por debulha na pré-colheita da cultura, pois o produto age como um fitorregulador de ação lenta que atua na liberação do etileno em contato com o tecido vegetal, abreviando o ciclo da cultura e fazendo com que essa esteja pronta para a colheita antecipadamente (SANCHES 2000).

$\mathrm{Na}$ busca por novos manejos de colheita de canola que reduzam as perdas de grãos em pré-colheita e colheita, têm se estudado os efeitos do adesionante, composto de látex + surfactante, isoladamente ou combinado aos herbicidas na dessecação química em pré-colheita (BOLLER et al. 2012). O adesionante funciona como um agente adesivo, favorecendo a deposição e a retenção do produto aplicado sobre as síliquas, isoladamente, e/ou da calda de aplicação (adesionante + dessecante + água), fixando e reduzindo o escorrimento da calda pela ação da chuva ou qualquer forma de irrigação por sobre a cultura (HAILE 2014).

O objetivo desse trabalho foi comparar cinco sistemas de manejo de colheita mecanizada em canola, com e sem a aplicação de um adesionante, avaliando perdas em pré-colheita e colheita, rendimento de grãos e teor de água nos grãos colhidos.

\section{MATERIAL E MÉTODOS}

O experimento foi conduzido na área experimental da Faculdade de Agronomia e Medicina Veterinária da Universidade de Passo Fundo (FAMV/UPF), município de Passo Fundo, RS. A semeadura foi realizada em 07/05/2014 e a emergência das plantas ocorreu em 12/05/2014. Foi utilizado o híbrido de canola Hyola 61, indicado pelo zoneamento agrícola para a região Norte do estado, sendo semeado e conduzido de acordo com as indicações técnicas oficiais (ZONEAMENTO 2012).

Para a semeadura utilizou-se trator com potência de $75 \mathrm{cv}$ e uma semeadora-adubadora de precisão com sete linhas. O espaçamento entrelinhas foi de $0,45 \mathrm{~m}$, a profundidade de semeadura de $0,02 \mathrm{~m}$, e a quantidade de sementes foi de $3,0 \mathrm{~kg} \mathrm{ha}^{-1}$ visando estabelecer uma população efetiva de 400.000 plantas por hectare.

O delineamento experimental foi o de blocos ao acaso, com arranjo fatorial $(5 \times 2)$, com quatro repetições. Os tratamentos resultaram da combinação de cinco manejos de pré-colheita e colheita, com ou 
sem a aplicação de um adesionante composto por surfactante + látex (Tabela 1). O experimento constou de 40 parcelas, cada uma medindo $10 \mathrm{~m}$ de comprimento por $3,15 \mathrm{~m}$ de largura, totalizando uma área de 31,5 $\mathrm{m}^{2}$, mantendo-se corredores de $1,0 \mathrm{~m}$ nas cabeceiras e lateralmente entre as parcelas.

Tabela 1. Sistemas de manejo em pré-colheita e colheita e doses de produtos aplicados ao híbrido de canola Hyola 61. FAMV/UPF, 2014.

Table 1. Pre-harvest and harvest managements techniques and product doses applied to Hyola 61 canola hybrid. FAMV/UPF, 2014.

\begin{tabular}{lcc}
\hline \multirow{2}{*}{ Manejo } & \multicolumn{2}{c}{ Dose $\left(\mathrm{L} \mathrm{ha}^{-1}\right)$} \\
\cline { 2 - 3 } & Com adesionante & Sem adesionante \\
\hline M1 - Testemunha - maturação natural & 1,0 & - \\
M2 - Dessecação com diquat & $2,0+1,0$ & 2,0 \\
M3 - Dessecação com glufosinato de amônio & $2,0+1,0$ & 2,0 \\
M4 - Corte-enleiramento & 1,0 & - \\
M5 - Aplicação de etefom & $0,5+1,0$ & 0,5 \\
\hline
\end{tabular}

Para a estimativa das perdas de pré-colheita e de colheita utilizaram-se bandejas medindo $63 \mathrm{~mm}$ de altura $\times 290 \mathrm{~mm}$ de largura $\times 370 \mathrm{~mm}$ de comprimento, posicionadas nas entrelinhas da cultura. Foram feitas perfurações com 3,0 mm de diâmetro nos cantos das bandejas, com a finalidade de escoar a água proveniente das chuvas. As bandejas foram posicionadas imediatamente após a realização dos manejos de pré-colheita comparados (corte-enleiramento e dessecação química prévia) sendo utilizadas três bandejas por parcela (inclusive naquelas onde foi realizada a colheita com corte direto no ponto de maturação natural).

As bandejas foram utilizadas com o intuito de estimar as perdas de pré-colheita e colheita, captando os grãos oriundos do desgrane natural, que é característico da cultura e das perdas ocasionadas por meio da colheita mecanizada (perdas na plataforma) e foram recolhidas imediatamente após a colheita. No manejo de corte-enleiramento, o enleiramento foi obtido por meio de três linhas, assim a massa de grãos coletada nas bandejas foi dividida por 3,0. Cada leira foi formada entre duas entrelinhas, perfazendo um espaçamento entre enleiramento de $0,90 \mathrm{~m}$.

Os manejos de colheita com corte-enleiramento, dessecação química prévia, e aplicação de etefom, foram realizados em 09/10/2014, quando $60 \%$ dos grãos dentro das síliquas do ramo principal (ápice da planta) mudaram da cor verde para a cor marrom. As plantas foram cortadas e enleiradas manualmente com o auxílio de foices, e a altura de corte determinada foi de $0,3 \mathrm{~m}$ em relação ao solo. As plantas cortadas foram suspensas sobre seus próprios caules dando origem as leiras. Imediatamente após a formação das leiras, na metade delas foi pulverizado o adesionante Grip ${ }^{\circledR} \mathrm{com} \circ$ auxílio de um pulverizador portátil pressurizado com $\mathrm{CO}_{2}$, equipado com barra, portando quatro pontas de pulverização de jato plano da série Teejet ${ }^{\circledR}$ XR11001. A pressão de operação foi de 2,5 bar $(250 \mathrm{kPa})$, gerando gotas de categoria fina e 0 volume de calda foi de $100 \mathrm{~L} \mathrm{ha}^{-1}$.

Foram utilizados os herbicidas glufosinato de amônio $\left(2,0 \mathrm{~L} \mathrm{ha}^{-1}\right)$ e diquat $\left(2,0 \mathrm{~L} \mathrm{ha} \mathrm{C}^{-1}\right)$ e o regulador de crescimento vegetal etefom $\left(0,5 \mathrm{~L} \mathrm{ha}^{-1}\right)$, isoladamente e/ou em conjunto com um adesionante $\left(\mathrm{Grip}^{\circledR}\right)$ à base de látex + surfactante $\left(1,0 \mathrm{~L} \mathrm{ha}^{-1}\right)$. Dentre as parcelas em que se utilizou o manejo de colheita com corte direto no ponto de maturação natural, metade recebeu a pulverização do adesionante, sete dias antes da colheita.

As pulverizações dos produtos foram realizadas com o auxílio do mesmo pulverizador portátil pressurizado com $\mathrm{CO}_{2}$. O volume de calda, os bicos e a pressão de pulverização utilizados foram idênticos aos usados no manejo de pré-colheita com corte-enleiramento.

A precipitação pluvial total ocorrida no mês de outubro foi de $156 \mathrm{~mm}$, sendo que, entre a realização do corte-enleiramento, a dessecação química prévia e a aplicação de etefom até a colheita, período de 12 dias, a precipitação foi de $133 \mathrm{~mm}$, e a velocidade média dos ventos no período foi de $3,8 \mathrm{~km} \mathrm{~h}^{-1}$ com picos de $7,5 \mathrm{~km} \mathrm{~h}^{-1}$, de acordo com dados registrados na estação agrometeorológica da Embrapa Trigo, Passo Fundo, RS.

Todas as colheitas foram realizadas quando aproximadamente $100 \%$ dos grãos estavam maduros e o seu teor de água encontrava-se entre 15 e 18\% (22/10/2014). Realizou-se essa operação por meio de uma colhedora automotriz de parcelas (Wintersteiger ${ }^{\circledR}$ ), com largura de plataforma de 1,5 m, colhendo-se as três 
linhas centrais de cada parcela. O recolhimento das leiras corte-enleiradas também foi realizado com o auxílio da mesma colhedora.

Após a colheita, o material foi levado ao Laboratório de Análise de Sementes (LAS) da Universidade de Passo Fundo, UPF, e passou pelos processos de pré-limpeza e limpeza através de peneiras com malhas de 3,0 mm de diâmetro. Também foi determinado o teor de água nos grãos colhidos em um aparelho eletrônico medidor de umidade (Gehaka $\mathrm{G} 810^{\circledR}$ ). Após a padronização do teor de água para $10 \%$, teor indicado para a comercialização dos grãos, a produção obtida em cada parcela experimental foi convertida em $\mathrm{kg}$ por hectare e dessa forma determinou-se o rendimento de grãos.

Concluído o processo de limpeza, a massa de grãos foi pesada, e os resultados foram extrapolados para $\mathrm{kg} \mathrm{ha}^{-1}$. Somando-se as perdas ao rendimento de grãos colhidos obteve-se a produção total. Dividindose as perdas pela produção total, estimou-se a porcentagem de perdas de cada tratamento.

Os resultados obtidos foram submetidos à análise de variância e as médias foram comparadas pelo teste de Tukey a $5 \%$.

\section{RESULTADOS E DISCUSSÃO}

A análise de variância (ANOVA) demonstrou haver respostas significativas aos sistemas de manejo da colheita e ao uso do adesionante. Também indicou a existência de interações significativas entre o uso do adesionante e os manejos da colheita. Isso quer dizer que a ação do adesionante foi dependente do sistema de manejo da colheita e que os manejos de colheita foram influenciados diferentemente pela ação do adesionante, na redução das perdas em pré-colheita e colheita, no rendimento de grãos e no teor de água nos grãos colhidos. Por outro lado, não houve diferenças significativas entre os blocos indicando ausência de efeito deste sobre os caracteres avaliados (Tabela 2).

As perdas de grãos na pré-colheita e na colheita indicaram que houve diferenças entre alguns manejos de colheita. A dessecação química prévia com os herbicidas diquat ou glufosinato de amônio, a aplicação de etefom, e o corte-enleiramento apresentaram perdas de pré-colheita e colheita inferiores à testemunha com colheita direta (Tabela 3).

Tabela 2. Resumo da análise da variância (ANOVA), quadrados médios, para perdas, rendimento de grãos e teor de água nos grãos colhidos de canola, híbrido Hyola 61. FAMV/UPF, 2014.

Table 2. Summary of analysis of variance (ANOVA) and averages squares, for: losses, grain yield and water content in grains harvested from canola, Hyola 61 hybrid. FAMV/UPF, 2014.

\begin{tabular}{lcccc}
\hline $\begin{array}{l}\text { Fontes de } \\
\text { variação }\end{array}$ & GL & $\begin{array}{c}\text { Perdas } \\
\left(\mathrm{kg} \mathrm{ha}^{-1}\right)\end{array}$ & $\begin{array}{c}\text { Rendimento de grãos } \\
\left(\mathrm{kg} \mathrm{ha}^{-1}\right)\end{array}$ & $\begin{array}{c}\text { Teor de água } \\
(\%)\end{array}$ \\
\hline Bloco & 3 & $892,45^{\mathrm{NS}}$ & $260,96^{\mathrm{NS}}$ & $0,00 \mathrm{NS}$ \\
Manejo & 4 & $187,387^{*}$ & $503,916^{*}$ & $40,87^{*}$ \\
Adesionante & 1 & $36,289^{*}$ & $62,101^{*}$ & $1,52^{*}$ \\
Man. x Ades. & 4 & $3,399^{*}$ & $5,424^{*}$ & $0,14^{*}$ \\
Resíduo & 27 & 776,3 & 1,557 & 0,00 \\
Total & 39 & - & - & - \\
\hline CV $(\%)$ & - & 4,98 & 7,87 & 61,6
\end{tabular}

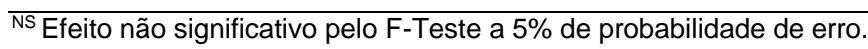

* Efeitos significativos pelo F-Teste a $5 \%$ de probabilidade de erro.

O manejo de corte-enleiramento, com ou sem a aplicação do adesionante apresentou as menores perdas de pré-colheita e colheita, quando comparada aos demais manejos utilizados (Tabela 3). Por sua vez, os manejos com dessecação e com aplicação do regulador de crescimento vegetal etefom proporcionaram perdas intermediárias entre o corte-enleiramento e a colheita no ponto de maturação natural, diferenciando-se desses dois manejos.

Quando utilizado o adesionante, em ambas as situações, tanto no corte-enleiramento como na colheita com corte direto na maturação natural, a redução nas perdas de colheita foi de aproximadamente $400 \mathrm{~kg} \mathrm{ha}^{-1}$, ou seja, uma redução de $46 \%$ entre as perdas de grãos na pré-colheita e colheita. Já, com a ausência da aplicação de adesionante nestes mesmos manejos de colheita, as perdas são de aproximadamente $450 \mathrm{~kg} \mathrm{ha}^{-1}$, gerando uma redução de até $44 \%$ entre as perdas de grãos na pré-colheita e colheita da canola.

Observou-se em virtude da ocorrência de chuvas, que totalizaram $133 \mathrm{~mm}$, no intervalo entre os 
manejos de pré-colheita e a colheita, que as perdas de grãos foram potencializadas. O manejo de colheita com corte-enleiramento apresentou menores perdas de grãos em relação a todos os tratamentos utilizados, por se tratar de uma forma de manejar as plantas totalmente diferente das demais utilizadas, concordando com estudos realizados por PARI et al. (2012), que avaliaram distintos métodos de manejo de colheita de canola, sob condições de intensa pluviosidade.

Tabela 3. Perdas de grãos $\left(\mathrm{kg} \mathrm{ha}^{-1}\right)$ de canola, híbrido Hyola 61, em pré-colheita e na colheita em função de cinco sistemas de manejo de pré-colheita e colheita. FAMV/UPF, 2014.

Table 3. Grain losses $\left(\mathrm{kg} \mathrm{ha}^{-1}\right)$ of canola, hybrid Hyola 61, under five different harvest-management treatments in pre-harvest and harvest. FAMV/UPF, 2014.

\begin{tabular}{lcc}
\hline \multirow{2}{*}{ Manejo } & \multicolumn{2}{c}{ Perdas $\left(\mathrm{kg} \mathrm{ha}^{-1}\right)$} \\
\cline { 2 - 3 } M1 - Testemunha - maturação natural & Com adesionante & Sem adesionante \\
M2 - Dessecação com diquat & B 512,6 b & A 810,8 a \\
M3 - Dessecação com glufosinato de amônio & B 505,6 b & A 615,1 b \\
M4 - Corte-enleiramento & A 354,2 c & A 603,5 b \\
M5 - Aplicação de etefom & B 512,4 b & A 356,5 c \\
\hline
\end{tabular}

Médias antecedidas pela mesma letra maiúscula na linha e médias seguidas de mesma letra minúscula dentro da coluna não diferem estatisticamente entre si pelo teste de Tukey a $5 \%$ de probabilidade de erro.

A prática de cortar e enleirar as plantas acelera e uniformiza a secagem dos grãos, além de reduzir as perdas por debulha, principalmente em condições climáticas adversas, através da formação de uma massa compactada e com a metade da altura das plantas que permanecem em pé em cultivos convencionais. Os demais manejos aplicados em pré-colheita da canola não apresentaram os efeitos desejados devido ao grande volume de chuvas ocorrido.

As perdas de grãos em pré-colheita e colheita no corte-enleiramento foram de $28 \%$, sendo essas as menores, quando comparado aos demais manejos utilizados (Tabela 4). Quando comparado ao manejo de colheita com corte direto no ponto de maturação natural apresentou redução de $48 \%$, concordando com os relatos de PORTELLA \& TOMM (2007) que após as plantas atingirem o ponto ideal para colheita (maturação fisiológica) podem ocorrer perdas significativas de cerca de $30 \%$ do potencial produtivo.

Tabela 4. Porcentagem de perdas de pré-colheita e colheita de grãos de canola, híbrido Hyola 61, em função de cinco sistemas de manejo de pré-colheita e colheita. FAMV/UPF, 2014.

Table 4. Percentage of pre-harvest and harvest losses of canola grains, hybrid Hyola 61, under five different harvest-management treatments in pre-harvest and harvest. FAMV/UPF, 2014.

\begin{tabular}{lcc}
\hline Manejo & \multicolumn{2}{c}{ Perdas (\%) } \\
\cline { 2 - 3 } & Com adesionante & Sem adesionante \\
\hline M1 - Testemunha - maturação natural & B 73,4 a & A 78,6 a \\
M2 - Dessecação com diquat & B 46,1 c & A 57,1 c \\
M3 - Dessecação com glufosinato de amônio & B 46,1 c & A 55,0 C \\
M4 - Corte-enleiramento & A 28,1 d & A 28,5 d \\
M5 - Aplicação de etefom & B 59,0 b & A 67,6 b
\end{tabular}

Médias antecedidas pela mesma letra maiúscula na linha e médias seguidas de mesma letra minúscula dentro da coluna não diferem estatisticamente entre si pelo teste de Tukey a $5 \%$ de probabilidade de erro.

Os manejos que proporcionaram perdas de pré-colheita e colheita menores, resultaram em rendimento de grãos maiores, como foi o caso específico da colheita com corte-enleiramento, onde o rendimento de grãos foi de aproximadamente $900 \mathrm{~kg} \mathrm{ha}^{-1}$. Essas observações concordam com os trabalhos de HAILE et al. (2014), segundo os quais a principal alternativa para a redução das perdas de pré-colheita e colheita é o corte-enleiramento, pois além de evitar as perdas por degrana que ocorrem a partir da maturidade fisiológica das plantas, reduz as perdas quando há ocorrência de temporais de vento e chuvas torrenciais as vésperas da colheita. Ainda, em relação ao manejo da colheita de canola com corteenleiramento, TOMM (2005) destaca que nesse manejo os grãos não ficam sujeitos ao atraso da colheita associado à variação da umidade do ar, e da alternância de ganho e perda de água nos grãos, prevenindo a ocorrência de rachaduras e do enrugamento do tegumento. 
De acordo com os estudos realizados por ESFAHANI et al. (2012) a dessecação química prévia com diquat reduz as perdas de grãos em pré-colheita e o teor de água nos grãos colhidos. No presente caso, os tratamentos baseados na dessecação química prévia, com os herbicidas diquat, ou com o glufosinato de amônio, e aplicação de etefom, não apresentaram o efeito esperado (redução das perdas de pré-colheita), devido ao excesso de chuvas e rajadas de vento (Tabela 5).

Tabela 5. Rendimento de grãos ( $\left.\mathrm{kg} \mathrm{ha}^{-1}\right)$ de canola, híbrido Hyola 61, com teor de água nos grãos corrigido para 10\%, em resposta a cinco sistemas de manejo de pré-colheita e colheita. FAMV/UPF, 2014.

Table 5. Grain yield ( $\left.\mathrm{kg} \mathrm{ha}^{-1}\right)$ of canola, Hyola 61 hybrid, grain water content corrected to 10\%, under five different harvest-management treatments in pre-harvest and harvest. FAMV/UPF, 2014.

\begin{tabular}{lcc}
\hline Manejo & \multicolumn{2}{c}{ Rendimento de grãos (kg ha $\left.{ }^{-1}\right)$} \\
\cline { 2 - 3 } & Com adesionante & Sem adesionante \\
\hline M1 - Testemunha - maturação natural & A 264,3 c & A 209,3 d \\
M2 - Dessecação com diquat & A 559,4 b & B 433,1 b \\
M3 - Dessecação com glufosinato de amônio & A 566,3 b & B 437,7 b \\
M4 - Corte-enleiramento & A 907,1 a & A 902,4 a \\
M5 - Aplicação de etefom & A 341,7 c & A 283,6 c \\
\hline
\end{tabular}

Médias antecedidas pela mesma letra maiúscula na linha e médias seguidas de mesma letra minúscula dentro da coluna não diferem estatisticamente entre si pelo teste de Tukey a $5 \%$ de probabilidade de erro.

O corte-enleiramento apresentou maior redução no teor de água nos grãos quando comparado aos demais manejos de colheita utilizados (Tabela 6), estando de acordo com os estudos realizados por TOMM et al. (2009) onde a formação de leiras permite o escorrimento da água dos grãos e a ventilação dos mesmos, acelerando o processo de secagem.

Tabela 6. Teor de água nos grãos colhidos de canola, híbrido Hyola 61, em resposta a cinco sistemas de manejo de pré-colheita e colheita. FAMV/UPF, 2014.

Table 6. Water content in grains harvested from canola, hybrid Hyola 61 under five different harvestmanagement treatments in pre-harvest and harvest. FAMV/UPF, 2014.

\begin{tabular}{lcc}
\hline \multirow{2}{*}{ Manejo } & \multicolumn{2}{c}{ Teor de água (\%) } \\
\cline { 2 - 3 } & Com adesionante & Sem adesionante \\
\hline M1 - Testemunha - maturação natural & A 14,9 d & B 14,6 e \\
M2 - Dessecação com diquat & A 13,5 b & A 13,3 b \\
M3 - Dessecação com glufosinato de amônio & A 14,8 d & B 14,1 c \\
M4 - Corte-enleiramento & A 19,6 a & B1 9,0 a \\
M5 - Aplicação de etefom & A 14,5 c & A 14,4 d \\
\hline
\end{tabular}

Médias antecedidas pela mesma letra maiúscula na linha e médias seguidas de mesma letra minúscula dentro da coluna não diferem estatisticamente entre si pelo teste de Tukey a $5 \%$ de probabilidade de erro.

Ainda, de acordo com a Tabela 6, a utilização do adesionante pode ter interferido na velocidade de secagem dos grãos, pois os grãos oriundos das plantas que foram tratadas com 0 adesionante apresentaram teor de água mais elevado. Uma possível explicação para isso, é que o mesmo possa retardar o efeito dessecante dos herbicidas e do regulador de etileno, retardando a velocidade de saída de água dos grãos.

\section{CONCLUSÃO}

Nas condições de pluviosidade excessiva verificadas no período que antecedeu a colheita, os manejos de colheita com corte-enleiramento, dessecação química prévia, e aplicação de etefom reduziram as perdas na colheita, quando comparados à testemunha (colheita na maturação natural), principalmente quando associados ao adesionante $\mathrm{Grip}^{\circledR}$. O manejo de colheita com corte-enleiramento associado ao adesionante Grip ${ }^{\circledR}$ foi o que trouxe maior redução nas perdas em pré-colheita e colheita de grãos, sendo essa, de aproximadamente $45 \%$ quando comparada à testemunha.

\section{REFERÊNCIAS}

BOLLER W et al. 2012. Colheita complicada. Cultivar Máquinas 11: 10-13. 
CANOLA. 2012. When to Swath, Winnipeg. Disponível em: <http://canola.okstate.edu/cropproduction/ harvesting/canola swathing_guide.pdf. Acesso em: 15 jun. 2016.

CANOLA. 2014. Swathing, Combining. Canola Council of Canada, Winnipeg. Disponível em: https://www.canolacouncil. org/canola-encyclopedia/managing-harvest/harvest-management/>. Acesso em: 15 jun. 2016.

CONAB. 2013. Companhia Nacional de Abastecimento. Acompanhamento da Safra Brasileira de Grãos: safra 2012/20 13. Disponível em: <http://www.conab.gov.br/OlalaCMS/uploads/arquivos/13_09_10_16_05_53_boletim_portugues_se tembro_2013.pdf>. Acesso em 10 jun. 2016.

CONTERJNIC S et al. 1991. Colza: cultivo, cosecha y comercialización. Buenos Aires: Departamento de Estudos y Prensa y Difusión de AACREA, CREA. 1991. 18 p. (Fascículo de divulgación).

DE MORI C et al. 2014. Aspectos econômicos e conjunturais da cultura da canola no mundo e no Brasil. Documento Online 149. Embrapa Trigo. Disponível em: <https://www.infoteca.cnptia.embrapa.br/handle/doc/988475>. Acesso em 11 jun.2016.

ESFAHANI M et al. 2012. Effects of pre-harvest application of parquat on grain moisture reduction, grain yield and quality of rapeseed (Brassica napus L.) cultivars. Caspian Journal of Enviromental Sciences 10: 75-82.

GARRAFA M. 2005. Aplicação de FMEA na otimização dos fatores de produção da cultura da canola. Dissertação (Mestrado em Engenharia da Produção). Santa Maria: UFSM. 166p.

HAILE TA et al. 2014. On-farm seed loss does not differ between windrowed and direct-harvested canola. Canadian Journal of Plant Science 94: 785-789.

KRÜGER CAMB et al. 2011. Arranjo de plantas na expressão dos componentes da produtividade de grãos de canola. Pesquisa Agropecuária Brasileira 46: 1448-1453.

LACERDA ALS et al. 2003. Aplicação de dessecantes na cultura da soja: teor de umidade nas sementes e biomassa nas plantas. Planta Daninha 21: 427-434.

PARI L et al. 2012. The harvest of oilseed rape (Brassica napus L.): The effective yield losses at on-farm scale in the Italian area. Biomass and Bioenergy 46: 453-458.

PORTELLA JA \& TOMM GO. 2007. Enleiramento e colheita de canola. Passo Fundo: Embrapa Trigo. (Embrapa Trigo. Documentos Online, 89). Disponível em: <http://www.cnpt.embrapa.br/biblio/do/p_do89.htm>. Acesso em: 5 jun. 2016.

SANCHES FR. 2000. Aplicação de biorreguladores vegetais: aspectos fisiológicos e aplicações práticas na citricultura mundial. Jaboticabal: FUNEP. 160p.

TOMM GO et al. 2009. Panorama atual e indicações para aumento de eficiência da produção de canola no Brasil. Passo Fundo: Embrapa Trigo (Embrapa Trigo. Documentos Online, 118). Disponível em: <http://www.cnpt.embrapa.br/biblio/do/p_do118.htm>. Acesso em: 22 jun. 2016.

TOMM GO. 2005. Situação em 2005 e perspectivas da cultura de canola no Brasil e em países vizinhos. Passo Fundo: Embrapa Trigo. 21p.

WENDLER C et al. 1992. Effect of glufosinate (phosphinothricin) and inhibitors of photorespiration on photosynthesis and ribulose-1,5-bisphosphate carboxylase activity. Journal of Plant Physiology 139: 666-671.

ZONEAMENTO. 2012. Zoneamento Agrícola Risco Climático para a cultura de canola no Estado do Rio Grande do Sul (safra 2012). Embrapa Trigo, Passo Fundo. Disponível em: <http://sistemasweb.agricultura.gov.br/sislegis/action/detal haAto.do?method=visualizarAtoPortalMapa\&chave=457545640>.Acesso em: 23 jun. 2016. 